\title{
Highly Effective Detection of 4-Nitrophenol by Tremella-like Indium Silver Sulfide Modified GCE
}

\author{
Pinghua Chen ${ }^{1,2}$, Yangming Shi, ${ }^{1,2}$, Xueqin Li ${ }^{1,2}$, Tao Wang ${ }^{1,2}$, Minghui Zhou ${ }^{2}$, \\ Enzhu Tian ${ }^{2}$, Wenli Wang ${ }^{2}$, Hualin Jiang ${ }^{1,2, *}$, Hongying shu ${ }^{2}$ \\ ${ }^{1}$ Key Laboratory of Jiangxi Province for Persistence Pollutants Control and Resources Recycle, \\ Nanchang 330063, PR China \\ ${ }^{2}$ College of Environmental and Chemical Engineering, Nanchang Hangkong University, Nanchang \\ 330063, PR China \\ *E-mail: hua20022000@126.com
}

doi: $10.20964 / 2018.07 .28$

Received: 30 March 2018 / Accepted: 9 May 2018 / Published: 5 June 2018

\begin{abstract}
A highly sensitive electrochemical sensor for 4-nitrophenol was established based on a tremella-like indium silver sulfide modified glassy carbon electrode (TLISS/GCE). Indium silver sulfide was facilely synthesized by co-precipitation. The morphology and phase of TLISS was investigated by scanning electron microscopy and X-ray diffraction. An electrochemical study was conducted by an electrochemical impedance spectroscopic technique, cyclic voltammetry and differential pulse voltammetry. The as-prepared sensor detected 4-nitrophenol with high accuracy, satisfactory reproducibility and good stability in wide range of 4-nitrophenol concentrations, and the determination limit $(3 \mathrm{~S} / \mathrm{m})$ was as low as $1.09 \mu \mathrm{M}$. In addition, tap and river waters were used to evaluate the practical application of the newly developed TLISS/GCE sensor, and high performance was also obtained. To the best of our knowledge, this is the first report regarding the 4-nitrophenol detection performance of indium silver sulfide. The method reported here is helpful for developing more highly effective 4-nitrophenol detection methods.
\end{abstract}

Keywords: Sensors; Indium silver sulfide; Modified GCE; 4-Nitrophenol

\section{FULL TEXT}

(C) 2018 The Authors. Published by ESG (www.electrochemsci.org). This article is an open access article distributed under the terms and conditions of the Creative Commons Attribution license (http://creativecommons.org/licenses/by/4.0/). 